Journal of Research in Technical Careers

December 2017, Vol. 1, No. 2.

(C) Authors

\title{
Quality Indicators Guiding Secondary Career and Technical Education Programs of Study
}

\author{
Xue Xing, Sara Shaw, Howard R. D. Gordon \\ University of Nevada, Las Vegas
}

\begin{abstract}
The purpose of this study was to examine quality indicators currently guiding the rigor of secondary career and technical education (CTE) programs of study in the United States. Quality indicators are desirable characteristics or expectations for a comprehensive and effective CTE program of study. As of May 2017, we were able to locate publicly accessible secondary CTE quality program standards/guidelines for 38 states. A majority $(n=24)$ updated their secondary CTE quality program standards/guidelines within the last five years (i.e., 2012-2017). Deductive content analysis was conducted to examine the 38 state profiles using the Association of Career and Technical Education (ACTE) Quality CTE Program of Study Framework 4.0 for coding purposes. Common quality elements and key quality indicators were identified from those state documents, which supplements the ACTE Framework. Implications and examples for practice are also discussed.
\end{abstract}

Keywords: career and technical education, programs of study, quality indicators, secondary programs

\section{Introduction}

Traditionally perceived as associated with low-level training and low-wage jobs, career and technical education (CTE) has long been underestimated in terms of educational resource allocation and efficacy to prepare a skilled workforce. Evidence has shown that participation in CTE programs significantly reduces high school dropout rates and provides students with extended learning experiences that connect what they learn to reallife scenarios (Association for Career and Technical Education, 2007; Office of Vocational and Adult Education, US Department of Education, 2012). Increased awareness of and positive image building for CTE have drawn increased attention from parents, researchers, and policymakers (Stone \& Lewis, 2012). High-quality CTE programs tend to provide rigorous programs of study to prepare youths and adults for postsecondary education and training and prepare them to be competent in a wide range of high-wage, high-skill, and high-demand careers (Oregon Employment Department, 2016).

What defines the rigor of a CTE program of study? A program of study is defined as "a comprehensive, structured approach for delivering academic and career and technical education to prepare students for postsecondary education and career success" (Office of Vocational and Adult Education, US Department of Education, 2012). The Carl D. Perkins
Career and Technical Education Act of 2006 (Perkins IV) requires that local recipients of Perkins funds must offer at least one program of study that: a) contains secondary and postsecondary education elements, b) aligns course content in a coordinated and non-duplicative way, c) provides opportunities to gain postsecondary credits, and d) leads toward an industry-recognized credential or a postsecondary certificate or degree.

Perkins IV monitors the quality of CTE programs of study and fund allocation by requiring states to report program accountability data annually. Each year, states need to submit a consolidated report which includes narrative responses, financial status reports, student enrollment and performance data, and program improvement plans. The Division of Academic and Technical Education (DATE) within the Office of Career, Technical, and Adult Education evaluates states' fiscal status, audit findings, grant award conditions, and performance data to determine the risk level (low, elevated, significant) of state CTE programs (Office of Career, Technical, and Adult Education Division of Academic and Technical Education, 2016). DATE assesses the effectiveness of state practice and monitors the investment and return of federal money.

Besides federal regulations, two national quality frameworks also discuss the rigor of secondary CTE programs of study, focusing on various aspects of those programs. Researchers proposed similar characteristics of a rigorous CTE program of study in the twenty-first century (Holzer, Linn, \& Monthey, 2013; Stone \& Lewis, 
2012). These characteristics include: a) rigorous curriculum guided by industry standards to prepare students to be both college- and career-ready; b) effective pedagogy providing contextualized and work-based learning experience for students; c) collaboration at all levels in partnership/advisory between school, industry, and community; and d) regulation of certification and professional development for CTE educators.

Perkins Program of Study Design Framework. The Perkins Program of Study Design Framework, issued in early 2010, is a critical effort to guide the rigor of program development and implementation for state administrators and local CTE providers (Office of Vocational and Adult Education, US Department of Education, 2010). The Perkins framework contains ten essential elements that represent the quality and comprehensiveness of a program of study. These elements were not designed to be mutually exclusive nor have equal priority (Office of Vocational and Adult Education, US Department of Education, 2010). The ten elements are:

1. Legislation and Policies

2. Partnerships

3. Professional Development

4. Accountability and Evaluation Systems

5. College and Career Readiness Standards

6. Course Sequences

7. Credit Transfer Agreements

8. Guidance Counseling and Academic Advisement

9. Teaching and Learning Strategies

10. Technical Skills Assessments

A self-assessment tool was published with the Perkins framework to gauge the program of study implementation and evaluation at both state and local levels. The self-assessment tool is in the form of rubrics and worksheets. For each quality element, multiple measurement criteria are listed in the rubric section. State administrators or local CTE providers need to determine the current program implementation status on a threepoint Likert scale (1=None, 2=In Progress, $3=$ Operational) as well as the level of importance of such implementation (1=Low, $2=$ Important, $3=$ Critical). After ranking the program using the rubric, state administrators or local CTE providers need to respond to a worksheet addressing several questions about reflection, selfassessment, and strategies for action planning. Results from such self-assessments identify aspects of a program of study that need improvement but also assist programs in establishing priorities and a possible timeline for improvement capacity.

ACTE Quality CTE Program of Study Framework. The Association of Career and Technical Education (ACTE) has also initiated a multi-step ongoing project to identify comprehensive and research-based quality indicators for CTE programs of study. ACTE staff researchers located 21 frameworks (mostly national frameworks) related to general CTE topics, such as programs of study, career pathways, career academies, and other education and workforce development systems. They identified consistent content elements for CTE programs as well as education and workforce development more broadly (ACTE, 2015). With careful review, inclusion of additional documents, and feedback from focus groups, ACTE published the pilot version of the Quality CTE Programs of Study Framework (version 4.0, last updated in March 2017) after the first three draft versions (ACTE, 2017). The pilot version contains a total of twelve quality elements with indicators within each element depicting aspects of CTE program of study design and implementation. The twelve elements are:

1. Standards-aligned and Integrated Curriculum

2. Sequencing and Articulation

3. Student Assessment

4. Prepared and Effective Program Staff

5. Engaging Instruction

6. Access and Equity

7. Facilities and Equipment

8. Business and community Partnerships

9. Career Development

10. Career and Technical Student Organizations

11. Work-based Learning

12. Data and Program Improvement

The twelve elements across the framework were designed to be mutually exclusive to the extent possible (ACTE, 2017). This framework is anticipated to be used for local CTE program of study self-evaluation and improvement, and serves as a general guidance for development of more robust tools for these purposes (ACTE, 2017). Using this framework for evaluation will require a collaborative effort from local secondary and postsecondary CTE educators, staff (e.g., career guidance professionals), and stakeholders (e.g., advisory group members). A local CTE administrator may serve as the primary point of contact to facilitate information gathering from colleagues. No self-assessment tool(s) nor specific measures for quality elements were published together with the ACTE framework.

Purpose of Study. Current national quality frameworks for CTE, built upon solicited review of existing national frameworks relevant to CTE in general and expert input, offer clear expectations for the rigor in designing, implementing, and evaluating secondary CTE programs of study. Despite existing overarching national frameworks, little is known about state implementation of these frameworks or their quality elements. The purpose of this study was to examine quality indicators that guided secondary CTE programs of study in state practice. Quality indicators are defined as desirable characteristics or expectations for a comprehensive and effective CTE program of study. We initiated a thorough review of state documents and conducted content analysis pertaining to secondary CTE quality program standards/guidelines across the nation.

Research questions that guided this study include: 
1. Which state departments of education published publicly-accessible secondary CTE quality program standards/guidelines, and when were those state documents, if available, last updated?

2. What quality elements can be synthesized from state documents, compared to elements in the ACTE framework?

3. What tools did states use for evaluating CTE programs of study, as indicated in state documents?

\section{Method}

Design. Content analysis represents a class of systematic coding and categorizing methods used to identify themes or patterns of textual information (Elo \& Kyngäs, 2008; Vaismoradi, Turunen, \& Bondas, 2013). Content analysis reduces lengthy text materials into manageable units of data. Therefore, researchers are able to make replicable and valid inferences from the data to its context with the purpose of describing the phenomenon, providing new insights, or representing facts. Inductive content analysis is used when there is little former knowledge nor a coding framework. Researchers generate themes and categories from data through careful and repeated examination and comparison of meanings from units of data (FinfgeldConnett, 2014). Deductive content analysis is often used when there is prior knowledge and researchers intend to test a theory or framework. Researchers organize data based on an existing, though alterable, theory or framework.

In this study, we used deductive content analysis to identify quality indicators for secondary CTE programs of study across the nation. We adopted the ACTE Quality CTE Program of Study Framework version 4.0 (ACTE, 2017) as our coding framework to compare and contrast quality indicators implemented by different states. We used the ACTE framework to assist in synthesizing quality elements and indicators from the content analysis. Results of this study could supplement the framework and benefit state use in the future.

Sample. We reviewed all 50 states' department of education career and technical education websites, and examined every document published on the website for publicly accessible secondary CTE quality program standards/guidelines. Any documents that required login account or were distributed internally to certain groups of people were not included in this study. The selection criteria for the target document(s) met at least one of the following: a) standalone or embedded standards/guidelines with quality indicators guiding local secondary CTE program-of-study design, review, and/or improvement; b) program assessment tool(s) illustrating indicators and/or measures that define the rigor for local secondary CTE program-of-study design, review, and/or improvement. These standards/guidelines as well as program assessment tools are issued mostly by a state eligible agency that governs career and technical education or workforce development (e.g., state CTE office) and are published on the state department of education websites. Therefore, those documents are recognized as statewide guidance for local CTE programs of study. Content analyses were conducted for those states that published quality program standards/guidelines.

Unit of Analysis. We created descriptions for the 12 quality elements and identified multiple key indicators associated with each quality element based on the ACTE framework. We used these descriptions as our coding instructions. The unit of analysis was the quality indicators that appeared in state documents. We kept written notations for each quality indicator and created an Excel worksheet to categorize states' quality indicators into appropriate quality elements based on our coding instructions.

When the quality indicator (unit of analysis) contained meaning crosswalks leading toward multiple quality elements, we followed the category system in the ACTE framework and referenced the context description in state documents in order to be as mutually exclusive as possible. The following provide examples of quality indicator statements and their categorization given the context of the statement:

1. Accommodations are made to facilities, equipment, curriculum, instruction, materials, and assessments to ensure all students have an opportunity to achieve success (categorized into No. 6 Access and Equity, and not No. 1 Standardsaligned and Integrated Curriculum, No. 3 Student Assessment, No. 5 Engaging Instruction, or No. 7 Facilities and Equipment).

2. Instruction of safety practices must be integrated and provided to each student. Teachers must attain and provide documentation and a record of all safety violations and student accidents (categorized into No. 7 Facilities and Equipment as it follows components of facilities and equipment safety and safety practice, and not No. 5 Engaging Instruction).

Trustworthiness. In content analysis, content validity and reliability are the most important indicators of trustworthiness of results. Reliability of content analysis is assured through inter-coder agreement of categories and replication of categorization at multiple times and occasions regardless of numbers and kinds of coders (Krippendorff, 2004). In this study, two coders worked independently. A repeated process was adopted for each coder to be consistent in his or her categorization at different times and occasions. Then, discrepancies of categorization were documented and each coder went back, referencing the coding instructions, and resolved disagreements. Eventually, data under consideration were agreeable between coders and were believed to be at least similarly interpretable by other scholars. 
Journal of Research in Technical Careers

Table 1. States with Secondary CTE Quality Program Standards/Guidelines by ACTE Region

\begin{tabular}{ccccccccccc}
\multicolumn{1}{c}{ Region I } & \multicolumn{2}{c}{ Region II } & \multicolumn{2}{c}{ Region III } & \multicolumn{2}{c}{ Region IV } & \multicolumn{2}{c}{ Region V } \\
\hline CT & - & AL & $2008 / 3$ & IA & $2010 / 8$ & AR & - & AK & $2010 / 8$ \\
DE & $2016 / 8$ & FL & - & IL & $2015 / 8$ & LA & - & AZ & $2014 / 4$ \\
MA & 2011 & GA & - & IN & $2002 / 12$ & MS & - & CA & $2015 / 9$ \\
MD & $2015 / 9$ & KY & $2017 / 3$ & MN & $2006 / 10$ & NM & $2015 / 3$ & CO & $2016 / 7$ \\
ME & $2010 / 8$ & NC & 2016 & MO & $2015 / 3$ & OK & - & HI & - \\
MI & $2015 / 9$ & SC & $2015 / 10$ & WI & $2011 / 7$ & TX & $2010 / 8$ & ID & $2016 / 9$ \\
NH & $2010 / 1$ & TN & $2013 / 8$ & & & & & KS & $2012 / 12$ \\
NJ & $2010 / 8$ & VA & - & & & & & MT & 2012 \\
NY & 2016 & & & & & & & ND & 2009 \\
OH & $2016 / 4$ & & & & & & & & NE & - \\
PA & $2016 / 4$ & & & & & & & & NV & $2016 / 10$ \\
RI & $2016 / 1$ & & & & & & & & OR & $2016 / 9$ \\
VT & $2016 / 12$ & & & & & & & & SD & 2010 \\
WV & - & & & & & & & & WA & $2013 / 5$ \\
& & & & & & & & & & \\
\end{tabular}

Note. - indicates that state did not publish publicly accessible secondary CTE quality program standards/guidelines as of 5/29/17. Date indicates when the state document was last updated (year/month).

\section{Results}

Research Question 1. Which state departments of education published publicly accessible secondary CTE quality program standards/guidelines, and when were those state documents, if available, last updated?

Of the 50 states examined, we were able to locate 38 states' (76\%) publicly accessible secondary CTE quality program standards/guidelines, which had been published on the state department of education website, as of 29 May 2017. Table 1 illustrates the 38 states by ACTE region. In the Northeast of United States (Region I), 12 out of 14 states (85.7\%) published secondary CTE quality program standards/guidelines; while in the Southeast (Region II), 5 out of 8 states (62.5\%) published their standards/guidelines. All 6 Midwest states (Region III, $100 \%$ ) and 2 out of 6 South states (Region IV, 33.3\%) published their quality standards/guidelines. In the West of United States (Region V), 13 out of 16 states (81.3\%) published their secondary CTE quality program standards/guidelines.

Among those 38 states that published quality CTE program standards/guidelines, six (i.e., Arizona, Maine, Iowa, New Hampshire, New Jersey, and Wisconsin) adopted the Perkins Program of Study Framework and its associated self-assessment tools (Office of Vocational and Adult Education, US Department of Education, 2010). Most of the 38 states had statewide, overarching quality program standards/guidelines for all secondary CTE programs of study. Other states had statewide quality program standards/guidelines targeting various stages of program development, career clusters/content areas, or types of evaluating personnel. For example, Delaware had separate subsets of quality standards for a program of study at the development stage and at the implementation stage. Montana not only had general program guidelines but also set up quality benchmarks for different content areas, while North Carolina only had quality standards for content areas. In Kentucky, Tennessee, and South Carolina, separate quality CTE program indicators were used by different types of evaluators such as teachers, administrators, and/or career counselors. In Washington, where CTE courses are divided into exploratory and preparatory natures, quality indicators were slightly different for those two types of courses.

In terms of the date of publication updates, 24 out of 38 states (63.2\%) have updated their secondary CTE quality program standards/guidelines within the last five years (i.e., 2012-2017). These states are Arizona, California, Colorado, Delaware, Indiana, Illinois, Kansas, Kentucky, Maryland, Michigan, Missouri, Montana, North Carolina, New Mexico, New York, Nevada, Ohio, Oregon, Pennsylvania, Rhode Island, South Carolina, Tennessee, Utah, and Vermont (see Table 1). Eleven states (28.9\%) have updated their 
Table 2. State Implementation of Secondary CTE Quality Program Elements

\begin{tabular}{|c|c|}
\hline Quality Elements & States \\
\hline 1. Curriculum & $\begin{array}{l}\text { AK, AL, AZ, CA, CO, DE, IA, ID, IL, IN, MA, MD, ME, MI, MN, MO, MT, NC, ND, } \\
\text { NH, NJ, NM, NV, NY, OH, OR, RI, SC, SD, TN, UT, VT, WA, WI }\end{array}$ \\
\hline 2. Sequencing & $\begin{array}{l}\text { AL, AZ, CA, CO, DE, IA, ID, IL, IN, KY, MA, MD, ME, MI, MO, MT, NC, ND, NH, } \\
\text { NJ, NM, NV, NY, OR, PA, RI, SC, SD, TN, VT, WI }\end{array}$ \\
\hline 3. Assessment & $\begin{array}{l}\text { AZ, CO, DE, IA, ID, IN, MA, MD, ME, MO, MT, NC, NH, NJ, NM, NY, OH, PA, RI, } \\
\text { VT, WI }\end{array}$ \\
\hline 4. Staff & $\begin{array}{l}\text { AK, AZ, CA, CO, DE, IA, ID, IL, IN, KS, KY, MA, ME, MI, MN, MO, MT, NC, ND, } \\
\text { NH, NJ, NM, NV, NY, OH, OR, PA, RI, SC, SD, TN, TX, UT, VT, WA, WI }\end{array}$ \\
\hline 5. Instruction & $\begin{array}{l}\text { AK, AL, AZ, CA, CO, DE, IA, IL, KS, MA, ME, MI, MN, MO, MT, NC, ND, NH, NJ, } \\
\text { NM, NV, OH, PA, RI, SC, SD, TN, VT, WI }\end{array}$ \\
\hline 6. Access and Equity & $\begin{array}{l}\text { AK, AL, CA, CO, ID, IL, MA, MI, MN, MT, ND, NM, NV, NY, OH, OR, SC, TN, TX, } \\
\text { UT, VT }\end{array}$ \\
\hline 7. Facilities & $\begin{array}{l}\text { AK, AL, CA, CO, DE, ID, IN, KS, MA, MI, MN, MT, NC, ND, NM, NV, OH, RI, SC, } \\
\text { SD, UT, VT, WA }\end{array}$ \\
\hline 8. Partnerships & $\begin{array}{l}\text { AL, AZ, CA, CO, DE, IA, ID, IL, IN, KS, KY, MA, MD, ME, MI, MN, MT, NC, ND, } \\
\text { NH, NJ, NM, NV, NY, OH, PA, RI, SC, SD, TN, TX, UT, VT, WI }\end{array}$ \\
\hline 9. Career Development & $\begin{array}{l}\text { AK, AZ, CA, CO, DE, IA, ID, IL, KY, MA, ME, MN, MT, NH, NJ, NM, NV, NY, OR, } \\
\text { PA, RI, SC, SD, TX, VT, WA, WI }\end{array}$ \\
\hline 10. CTSOs & $\begin{array}{l}\text { AL, CA, CO, DE, ID, KY, MA, ME, MI, MN, MO, MT, NC, ND, NM, NV, OH, OR, } \\
\text { SC, TN, UT, VT, WA }\end{array}$ \\
\hline 11. WBL & $\begin{array}{l}\text { AL, CA, CO, ID, IN, KY, MA, ME, MI, MN, MT, NC, ND, NM, NV, NY, OH, RI, SC, } \\
\text { SD, VT }\end{array}$ \\
\hline 12. Data and Program & $\begin{array}{l}\text { AZ, CA, CO, DE, IA, ID, IL, MA, MD, ME, MN, MO, MT, NC, NH, NJ, NM, NV, NY, } \\
\text { OH, OR, PA, SC, SD, TX, WI }\end{array}$ \\
\hline 13. Legislation & AK, AZ, IA, MA, ME, NH, NJ, PA, RI, WI \\
\hline 14. Administration & $\begin{array}{l}\text { AK, AL, CA, CO, DE, ID, KY, MA, MD, MI, MN, MO, MT, NC, ND, NM, NV, OH, } \\
\text { SC, SD, TN, UT, VT }\end{array}$ \\
\hline
\end{tabular}

Note. $\mathrm{CTSO}=$ career and technical student organization, $\mathrm{WBL}=$ work-based learning

quality CTE standards/guidelines within the last five to ten years (i.e., 2007-2011), specifically, Alaska, Alabama, Iowa, Massachusetts, Maine, North Dakota, New Hampshire, New Jersey, South Dakota, Wisconsin, and Texas. There are also three states $(7.9 \%)$ that have not updated their standards/guidelines in the past 10 years (before 2007), i.e., Indiana, Minnesota, and Washington.

Research Question 2. What quality elements can be synthesized from state documents, compared to the elements in the ACTE framework?

Through content analysis we identified 12 quality elements that conform to those in the ACTE framework, therefore, we adopted the names of those 12 elements. In addition, we synthesized two more quality elements from the analysis of state documents that do not fit into the ACTE framework and named them Legislation and Policies and Program Administration. We created and modified the description for each quality element and added new key indicators that were synthesized from the content analysis. The Appendix shows the new framework with an overview of quality elements and their key indicators, synthesized from state practice across the nation. Additional elements and indicators that were identified from the content analysis but not in the ACTE framework are included in our framework in italics. We also marked states that supported those indicators based on the information from state documents. Table 2 illustrates state implementation of these quality elements.

Legislation and Policies is a quality element that is also used in the Perkins Program of Study Design Framework (Office of Vocational and Adult Education, US Department of Education, 2010), requiring legislation and policies to be in place to guide the development, approval, implementation, evaluation, and improvement of CTE programs of study. Legislation and policies could also cover specific program running topics or at least provide resources and examples of successful practice in the state. For example, policies could explicate specific student outcome data that needs to be reported or identify procedures for the review and evaluation of student outcome data. Further instructions could be in place to include types and definitions for all student performance data, calculation methods, reporting procedures, benchmarks for passing/needs improvement, or even the 
Journal of Research in Technical Careers

Table 3. Count of States Implementing Quality Elements

\begin{tabular}{lcc} 
Quality Elements & Count of States & Rank \\
\hline 1. Curriculum & 34 & 2 \\
2. Sequencing & 31 & 4 \\
3. Assessment & 21 & 11 \\
4. Staff & 36 & 1 \\
5. Instruction & 29 & 5 \\
6. Access and Equity & 21 & 11 \\
7. Facilities & 23 & 8 \\
8. Partnerships & 34 & 2 \\
9. Career Development & 27 & 6 \\
10. CTSOs & 23 & 8 \\
11. WBL & 21 & 11 \\
12. Data and Program & 26 & 7 \\
13. Legislation & 10 & 14 \\
14. Administration & 23 & 8 \\
\hline
\end{tabular}

Table 4. Secondary CTE Program of Study Quality Evaluation Tools

\begin{tabular}{llc}
\hline Tool & \multicolumn{1}{c}{ States } & Count \\
\hline 1. Benchmark & AK, AL, CO, IL, IN, MO, MD, ND, NH, NJ, MT, PA, TN, & 15 \\
2. Rubric only & TX, VT & 12 \\
3. Checklist & DE, ID, KS, KY, ME, MN, NC, NV, OH, RI, UT, WI & 6 \\
4. Rubric \& Worksheet & CA, MA, MD, MI, OR, SC & 3 \\
5. Worksheet only & AZ, NM & 2 \\
\hline
\end{tabular}

requirement of actions required to address student achievement gap.

Program Administration as a quality element defines the roles and support systems that need to be in place for district and school administrators to coordinate and supervise CTE programs of study. The content analysis revealed that program administration focuses on defining the roles of administrators in areas of: a) coordinating advisory committee(s) and relevant staff to routinely communicate and collaborate on updates of curriculum, instruction, extended learning opportunities, assessments, labor market need projection, etc.; b) coordinating between teacher and school/district administration on the management of funding, program inventory, fiscal records, and instructional leadership in accordance with CTE policies and guidelines; c) guiding the development of local written program five-year plans and updates; and d) supervising student recruitment and program sustainability plans, including CTE educators' professional development activities and resources.

Overall, at least four and up to 13 quality elements were adopted by each state that had published publicly accessible secondary CTE program standards/guidelines. The average number of implementing states rounded up to 26 per quality element. Table 3 illustrates the count of states implementing each quality element. Element No. 4 Prepared and Effective Program Staff was found to be adopted by most states ( $n=36)$, accounting for $94.7 \%$ of states with publicly accessible CTE program standards/guidelines, while element No. 13 Legislation and Policies was adopted by least states $(n=10,26.3 \%)$.

Research Question 3. What tools did states use for evaluating CTE programs of study, as indicated in state documents?

Of the 38 states that had published secondary CTE quality program standards/guidelines, 23 states (60.5\%) also published the corresponding assessment tool for program evaluation. Assessment tools were in the form of a rubric, checklist, worksheet, or a combination of rubric and worksheet. Rubric was the most commonly used tool to evaluate secondary CTE programs of study in the United States. States that used only rubrics as the assessment tool accounted for $31.6 \%$ of the 38 states. Six states (15.8\%) adopted checklists, two states (5.3\%) used worksheets, and three states (7.9\%) combined rubrics and worksheets in their assessment. For those states that only published quality program standards/guidelines but did not address specific tool(s) for assessment, we found quality statements for those indicators. Those statements 
were often accompanied with resources for successful implementation and examples. We identified such situations as using benchmarks for the purpose of program evaluation, which accounted for $39.5 \%$ of the 38 states (Table 4).

\section{Discussion}

As of 2017, it appears that this is the first study that examined state implementation of quality elements in defining the rigor of secondary career and technical education (CTE) programs of study on a national level. We searched all 50 state department of education career technical education webpages for our target state document(s). Some states use different terminology (e.g., career technology education or career technical agriculture education), so we accommodated such terms in our search. We were not able to locate 12 states' secondary CTE quality program standards/guidelines on their state department of education websites. Those 12 states were Arkansas, Connecticut, Florida, Georgia, Hawaii, Louisiana, Mississippi, Nebraska, Oklahoma, Virginia, West Virginia, and Wyoming.

However, readers should not conclude that there is a lack of quality standards/guidelines for secondary CTE programs of study in those states. It is possible that these states adopt different development and evaluation systems for CTE programs of study or that quality program guidelines are only accessible to certain personnel (e.g., local administrators). For example, Georgia Department of Education has established a FiveYear Local Plan Application to identify strategies (e.g., funding sources, uses of funds, core indicators) to be implemented annually for program improvement purposes (Georgia Department of Education, 2008). The Local Plan also includes a status report, which annually updates the progress toward established strategies and performance measures.

We identified 14 common quality elements and their key indicators across the nation through content analysis of state department of education documents with public access. This study provides a comprehensive picture of state practice in regulating the design and review process of local secondary CTE programs of study. The top five implemented quality elements across the nation were: No. 4 Prepared and Effective Program Staff $(n=36)$, a tie of No. 1 Standards-aligned and Integrated Curriculum \& No. 8 Business and Community Partnerships $(\mathrm{n}=34)$, No. 2 Sequencing and Articulation $(\mathrm{n}=31)$, and No. 5 Engaging Instruction ( $\mathrm{n}=29$ ). Results of this study are consistent with CTE researchers proposed characteristics of high-quality CTE programs of study (Holzer, Linn, \& Monthey, 2013; Stone \& Lewis, 2012). Quality element No. 11 Work-based Learning $(\mathrm{n}=21)$ has raised increasing attention from educators and administrators, requiring CTE programs of study to provide work-based learning experiences for students to develop academic, technical, and employability skills.
Legislation and policies at the state and local level play an important role in regulating, promoting, and supporting state and local practices. Most states have separate legislation and policy regulation document(s) specifying various aspects of local CTE programs of study implementation. However, only a few states used legislation and policy as a component to define and evaluate the rigor of CTE programs of study. Highquality programs of study result from seamless coordination and collaboration across state, local, and stakeholder agencies, on topics such as determining high demand jobs, dedicating funds, and seeking input from industry in curriculum development (Office of Vocational and Adult Education, US Department of Education, 2010). State and/or local regulations and specification of major responsibilities of administration may improve communication and collaboration between relevant parties.

In terms of quality assessment, a rubric was the most widely used tool. Rubrics can be used alone or combined with worksheets with extra space for notes and comments. The remainder of the 15 states (39.5\%) did not address specific tools for assessment in their statewide documents of CTE program quality indicators. In this study, we identified those states as using benchmarks for program assessment, given available description of quality elements and indicators and link to recourses of successful examples and practices. However, further investigations should be conducted through additional information sources for CTE programs of study evaluation tools and approaches in those states.

Implications for Practice. The quality elements and indicators in the Appendix are aligned with the ACTE initiative of establishing quality CTE program of study and promoting best practices within CTE (ACTE, 2017). The new framework, shown in the Appendix, is organized around 14 quality elements of a comprehensive and effective CTE program of study. Each quality element was defined and interpreted by key quality indicators that were phrased as mutually exclusive as possible. The Appendix further supplements the ACTE framework through a thorough review of current state implementation practice, which is an alternative to ACTE's research-oriented approach by reviewing existing national frameworks.

We recommend state administrators and collaborative parties adapt our framework to establish and/or revise statewide secondary CTE program of study guidelines and the program of study evaluation system. We recommend that relevant parties further expand our framework into a quality CTE program of study ElementIndicators-Measures model. For example, CTE personnel in a state department of education could initiate collaboration between relevant stakeholders and researchers to establish specific measures for each quality indicator that are meaningful to each state. In the meantime, state administrators and collaborative parties 
could reference Table 2 for relevant state profiles of quality indicators pertaining to a specific quality element in question. They may also accommodate other states' program of study guidelines.

State department of education and district CTE coordinators should collaborate to identify systematic evaluation procedures assessing the quality of local programs of study on a regular basis. The whole program self-assessment package covering all 14 quality elements, once submitted, shall undergo a series of evaluation procedures by a special committee organized by the state department of education. Evaluation procedures may include desk reviews, site visits, and reports of results.

For local educational agencies, using our framework for program assessment will require information input from all parties, such as CTE educators, career counselors, and school administrators. A local CTE administrator may take responsibility to facilitate information gathering from all parties and generate a consolidated report. It is also worth modeling the quality elements and indicators in the framework and searching relevant state practices for local innovative use. For example, local schools could improve schoolwide program of study policies and procedures by accommodating state policies and procedures. Local schools could also monitor schoolwide CTE programs of study quality control by accommodating effective quality indicators and measures to local situations, which, in turn, could be used in program promotion and reporting.

From the content analysis of state quality CTE program of study documents, we recognized some good state practice in regulating quality CTE programs of study and, especially, the specific measures those states adopted for program evaluation. We would like to highlight a few examples of successful state practice.

Delaware: State-Model \& Self-Developed Program of Study. The Delaware Department of Education developed a series of state-model CTE programs of study with the input of the advisory committee that represents various stakeholders in the community. Each state-model CTE program of study aims at a career pathway and suggests the course sequence, opportunities for early college and industry-recognized credentials, support from school administrators and counselors, and coursespecific teacher professional development opportunities (Delaware Department of Education, n.d.). Local educational agencies (LEAs) can adopt these basic state models or develop their own CTE programs of study. For the latter, the Delaware Department of Education CTE \& STEM Office regulates the quality of the program of study and evaluates within the five-year review cycle. Those regulations apply to all state-model and selfdeveloped CTE programs of study, which govern the rigor at three phases: program development, implementation, and continuous improvement. During the phases of program development and implementation, LEAs are provided with quality indicators, guiding questions, rubrics for weak and strong practice, and potential metrics demonstrating effective practices (Career \& Technical Education and STEM Office, Delaware Department of Education, 2016). Specific guidance and procedures for program of study application, adoption, or development are explained in the Delaware CTE Programs of Study Policies and Procedures (Delaware Department of Education, n.d.) with accessible reference and resource links.

Potential metrics demonstrating effective practices offer valuable input to quantify measures of every quality indicator. For example, potential metrics demonstrating effective professional learning content and pedagogy for CTE educators and relevant staff (Phase 2 Implementation-C4) include:

- Type/impact of interactions between teachers and industry partners;

- $\quad$ Type/impact of professional development opportunities for counselors and administrators;

- Number/impact of content specific professional development opportunities for CTE teachers; and

- Number/impact of teacher externship opportunities.

Potential metrics for the impact of professional learning of teachers on student achievement (Phase 2 Implementation-C5) include:

- $\quad$ Percentage of teachers reporting that professional development had an impact on student learning;

- $\quad$ Percentage of CTE students showing improvement as a result of teacher professional development related to Perkins indicators;

- $\quad$ Percentage of CTE students showing improvement as a result of teacher content knowledge and skill development; and - $\quad$ Percentage of CTE students showing improvement as a result of teacher professional practice or instructional coaching.

New York: Work-based Learning. In New York State, the work-based learning (WBL) component of a program of study is not only mentioned in the Course Sequence section but is also a section by itself detailing various aspects of rigorous work-based learning experiences (New York State Department of Education, n.d.). A program of study contains a formal and structured work-based learning scope and sequence, which shows a progression of rich and varied practical experiences. These experiences range from career exploratory activities, job readiness training, mentoring and industry-based competitions, to internships. The WBL scope and sequence builds systematically on school-based curriculum that aligns with academic and industry skill standards. Students, regardless of academic ability, race, gender, ethnicity or disability, have access to a varied range of information, opportunities, and examples of highly successful WBL experiences. Students could make decisions and placements tailored to their needs. Clear guidance is available to students, 
parents/guardians, and employers in preparation for WBL. Well-established partnerships with one or more hosts are available to provide industry-appropriate assignments for students. For internships, there is a clear link between the student training plan and the student performance evaluation with the employer. Evaluation of the WBL quality is systematic, routine to the school, and draws on both employers' and students' views (see indicators guiding work-based learning in New York).

We believe successful work-based learning models should be built upon a holistic top-down system with federal and state's legislation and funding support, administrative support, and schoolwide structured workbased learning scope and sequence. Local policies should allow flexible schedules for teachers, provide orientation and professional development for teachers and WBL coordinators for student placement, and arrange communication between industries, schools, and parents. All of these components could be developed by state and school administrators and collaborative parties into quality indicators and quantifiable measures for effective work-based learning experiences of a CTE program of study.

Nevada: Specification of Student Outcome Data. In the ACTE framework, there is no specification for what accounts for student outcome data. Perkins IV requires states to report on eight student performance core indicators (Office of Vocational and Adult Education, US Department of Education, 2010). Assuming all states collect the required student performance data, additional data may be collected to provide valuable input for evaluating the program quality. Nevada provides insight into what some of the student outcome data may look like in its CTE Quality Program Standards (QPS) (Office of Career Readiness, Adult Learning \& Education Options Nevada Department of Education, 2016). State and school administrators can define and develop student outcome data that accommodates specific scenarios, for example:

- $\quad$ QPS 8.2 Student Feedback

- QPS 8.3 Student Follow-up

- QPS 8.4 Retention and Completion

- $\quad$ QPS 8.5 Workplace Readiness Skills

Assessment Participation Rate

- $\quad$ QPS 8.6 Workplace Readiness Skills

Assessment Pass Rate

- $\quad$ QPS 8.7 End-of-Program Technical

Assessment Participation Rate

- $\quad$ QPS 8.8 End-of-Program Technical

Assessment Pass Rate

- $\quad$ QPS 8.9 Certificate of Skill Attainment

Limitations. Readers should exercise caution when interpreting the results of this study.

1. Readers may not conclude that there is a lack of program quality for those 12 states for which we could not locate published publicly accessible program standards/guidelines.
2. We acknowledge that all state department of education organize content differently. It is possible the target document was missed because it was located elsewhere or the information was dated due to the lack of website updates.

3. Occasionally, there was no date of publication or updates indicated in a state document, nor was the date could be found on the website. We cross-referenced some relevant state documents that referred the target document and its updates. However, we still could not locate all the date of updates.

Recommendations for Future Research. This study used content analysis to investigate state implementation of quality elements for secondary CTE programs of study. Future research may investigate quality indicators guiding various types of postsecondary CTE programs (e.g., technical or applied science associate degree programs). In terms of CTE program of study assessment tools, rubrics were most widely used by state and local administrators. Fifteen states did not address specific methods or tools for assessment aside from a description of quality elements or indicators. Further investigations should be conducted on the evaluation tools and approaches for CTE programs of study in these states.

\section{References}

Association for Career and Technical Education. (2007, June). CTE's role in dropout prevention and recovery. Alexandria, VA: Author.

Association of Career and Technical Education. (2015, July). Defining high-quality CTE: Contemporary perspectives on CTE quality. Alexandria, VA: Author.

Association of Career and Technical Education. (2017, March). Defining high-quality CTE: Quality CTE program of study framework version 4.0 (beta). Alexandria, VA: Author.

Career \& Technical Education and STEM Office, Delaware Department of Education. (2016). Delaware department of education CTE programs of study policies and procedures. Retrieved from https://www.doe.k12.de.us/Page/435

Delaware Department of Education. (n.d.). Selfassessment for career and technical program of study. Retrieved from https://www.doe.k12.de.us/Page/435

Elo, S., \& Kyngäs, H. (2008). The qualitative content analysis process. Journal of Advanced Nursing, 62, 107-115. doi:10.1111/j.1365-2648.2007.04569.x

Finfgeld-Connett, D. (2014). Use of content analysis to conduct knowledge-building and theory-generating qualitative systematic reviews. Qualitative Research, 14, 341-352. doi:10.1177/1468794113481790 
Georgia Department of Education. (2008). Georgia State Plan: FY 2009-2013 (July 1, 2008-June 30, 2013). Retrieved from http://archives.gadoe.org/DMGetDocument.aspx/St ate\%20Plan\%202007\%20FINAL.pdf?p=6CC6799 F8C1371F683D35AA53FB4C84E1700E790CB38 F87DDC965399A2D6BD74\&Type=D

Holzer, H. J., Linn, D., \& Monthey, W. (2013). The promise of high-quality career and technical education. Retrieved from The Georgetown Law Center on Poverty, Inequality, and Public Policy website: http://www.sdlcillinois.org/constitution/georgetown .pdf

Krippendorff, K. (2004). Reliability in content analysis: Some common misconceptions and recommendations. Human Communication Research, 30, 411-433.

New York State Department of Education. (n.d.). Career and technical education program selfevaluation form. Retrieved from http://schools.nyc.gov/ChoicesEnrollment/SpecialP rograms/CTE/Educators/The+Program+Approval+ Process.htm

Office of Career, Technical, and Adult Education Division of Academic and Technical Education. (2016). FY 2017 monitoring plan for state formula grants funded under the Carl D. Perkins Career and Technical Education Act of 2006 (Perkins IV). Retrieved from https://s3.amazonaws.com/PCRN/docs/FY_2017_P erkins_IV_Monitoring_Plan.pdf

Office of Career Readiness, Adult Learning \& Education Options, Nevada Department of
Education. (2016). Quality program standards. Retrieved from http://www.doe.nv.gov/uploadedFiles/ndedoenvgov /content/CTE/Documents/Quality-ProgramStandards-ADA.pdf

Office of Vocational and Adult Education, US Department of Education. (2010). Programs of study: Local implementation readiness and capacity. A tool for local college and career readiness. Retrieved from http://www.ksde.org/Portals/0/CSAS/CSAS\%20Ho me/CTE\%20Home/Perkins/Reserve_Funds_RPOS/ POS\%20Local\%20Readiness\%20Intro.pdf?ver=20 13-12-03-142720-777

Office of Vocational and Adult Education, US Department of Education. (2012). Investing in America's future: A blueprint for transforming career and technical education. Retrieved from https://www2.ed.gov/about/offices/list/ovae/pi/cte/t ransforming-career-technical-education.pdf

Oregon Employment Department. (2016). High-wage, high-demand, and high-skill occupations. Retrieved from http://library.state.or.us/repository/2016/201603081 037102/index.pdf

Stone, J. R., \& Lewis, M. V. (2012). College and career ready in the 21st century: Making high school matter. New York: Teachers College Press.

Vaismoradi, M., Turunen, H., \& Bondas, T. (2013). Content analysis and thematic analysis: Implications for conducting a qualitative descriptive study. Nursing and Health Sciences, 15, 398-405. doi:10.1111/nhs.12048 


\section{Appendix \\ Quality Indicators of Secondary CTE Programs of Study}

Note: Additional elements and indicators identified from the content analysis are included in italics.

\section{Element 1: Standards-aligned and Integrated Curriculum}

Description: Curriculum of the career and technical education (CTE) program of study is developed with employer input, is industry-validated and integrated with core subject content for the development of appropriate and relevant work-place readiness skills that are applicable to the latest advances in the field.

\section{Key Indicators:}

1. Based on industry-validated technical standards and competencies

2. Alignment with relevant content standards for core subjects

3. Incorporation of employability skills standards

4. Application of knowledge and skills in authentic scenarios

5. Publically available and accessible

6. Reviewed and revised regularly to reflect the latest advances in the field

7. Integration of academic and career and technical curriculum (e.g., AZ, DE, ME, TN)

\section{Element 2: Course Sequencing and Articulation:}

Description: The CTE program of study sequences courses, develops stackable credentials, and vertically aligns curriculum seamlessly through secondary and postsecondary education.

\section{Key Indicators:}

1. Non-duplicative and vertically aligned courses across secondary and postsecondary education

2. Appropriate sequence of courses starting with broad foundational knowledge and skills and progressing to occupational specific knowledge and skills

3. Leading to postsecondary credentials such as industry certifications and postsecondary degrees

4. Opportunities to earn postsecondary credits while in high school

5. Regular collaboration between CTE educators and advisory committee on course sequencing, articulation, and dual enrollment

6. Coordinated with career pathway systems

7. Formal articulation agreements support credit attainment and transfer of credits among secondary and postsecondary institutions (e.g., AZ, CA, IA, IL, NM, KY, ME, MO, ND, NH, NJ, PA, RI, SC, TN, VT, WI)

\section{Element 3: Student Assessment:}

Description: The CTE program of study implements multiple forms of student assessments, which are aligned with relevant program curriculum and standards.

\section{Key Indicators:}

1. Multiple forms of assessment integrated throughout the program of study

2. Program standards and curriculum assessment alignment

3. Ensured assessments' validity and reliability in accordance with relevant quality standards

4. Objective information on student attainment of academic, technical, and employability knowledge and skills

5. Preparation for recognized postsecondary credentials

Element 4: Prepared and Effective Program Staff:

Description: Educators in the CTE program of study meet minimum state, district, and/or institutional licensing and requirements, have appropriate industry-relevant credentials, and maintain evidence-based pedagogical knowledge and skills through professional and leadership developmental activities.

\section{Key Indicators:}

1. Meeting state, district, and/or institution certification and licensing requirements

2. Maintaining industry-relevant credentials which are up-to-date

3. Maintaining relevant pedagogical knowledge and skills

4. Engaging in professional and leadership development on a wide range of topics

5. Having time, resources, and support to implement high-quality CTE program of study

6. Regular coordination with academic educators, counselors, administrators, and other relevant staff for curriculum, instruction, assessment updates and data analysis for program improvement

7. Using technology (e.g., webinars, open educational resources, and other web-based sources) to ensure professional development is widely accessible and affordable to diverse types of faculty and staff (e.g., IL)

8. $\quad$ Continual professional growth plan with career pathway-focused (e.g., KS) 
Element 5: Engaging Instruction:

Description: Instruction of the CTE program of study is guided by content area standards and learning objectives using project-based learning and contextualized instructional approaches that promote problem-based, inquiry-based, and challenge-based learning. Instruction incorporates relevant technologies, equipment, and materials and provides differentiated and personalized educational experiences to meet the needs of a diverse population.

Key Indicators:

1. Relevant content area standards and learning objectives

2. Problem-based, inquiry-based and challenge-based approaches

3. Contextualized instruction

4. Cross-disciplinary collaboration

5. Differentiated and personalized instruction

6. Available equipment, technology, and materials

\section{Element 6: Access and Equity:}

Description: The CTE program of study is promoted to all potential students and/or parents, free from bias, all-inclusive and non-discriminatory with appropriate modifications, accommodations, and support services to ensure all students have an opportunity to achieve success.

\section{Key Indicators:}

1. Program access free from bias, inclusive, and non-discriminatory

2. Underrepresented population recruitment, including gender, race and ethnicity, and special population

3. Accommodations to facilities, equipment, curriculum, instruction, materials, and assessments

4. Career guidance, support services, tutoring, and transportation assistance

5. Eliminating barriers to extended learning experiences, such as work-based learning, student activities, postsecondary credit attainments, for all students

\section{Element 7: Facilities and Equipment:}

Description: Facilities and equipment used in the CTE program of study reflect current workplace and industry practices and align to curriculum standards and program objectives. Facilities and equipment meet federal, state, local standards for occupational safety and health and all Title IX, Americans with Disabilities Act, and other accessibility requirements.

Students demonstrate safe and appropriate use of facilities and equipment.

Key Indicators:

1. Reflecting current workplace, industry and/or occupational practices and requirements

2. Supporting curriculum standards and program objectives

3. Meeting federal state, local standards for occupational safety and health, as applied in the related industry

4. Maximum access to relevant facilities and equipment

5. Regular inspections, updates and replacements of equipment, as necessary

6. Students demonstrating safe and appropriate use and maintenance of facilities and equipment

7. Instruction of safety practices must be integrated and provided to all student and staff. Teachers must attain and provide documentation and a record of all safety violations and student accidents (e.g., CO, ID, IN, MA, MI, SC)

8. Available managing system to monitor budget, inventory, and storage of equipment and materials (e.g., $A L, D E$, $N C, N D, N M, S C, S D)$

Element 8: Business and Community Partnerships:

Description: The CTE program of study has a formalized and structured approach to coordinate partnerships with the community to ensure student, community, and workforce needs.

Key Indicators:

1. Active outreach activities to develop partnerships

2. Containing the advisory committee that represents diverse range of community employers and stakeholders

3. Defined duties of the advisory committee

\section{Element 9: Career Development:}

Description: The CTE program of study contains career development guidance and counseling services, which are personalized, sequenced, and aligned to meet and support student interest, preferences and abilities. Students have access to job search information, extended learning experiences, training, and educational trends.

Key Indicators:

1. Comprehensive career development guidance coordinated and sequenced, both prior to entering and during the program of study

2. Personalized, multiple-year education and career plan for all students 
3. Career development activities alignment with national, state, and/or local standards

4. Accessible job search information, placement service, extended learning experience and training for further career opportunities and earning outcomes

5. Up-to-date guidance, counseling and advisement service

6. Parental involvement is part of student decision-making process (e.g., MA, NM, TX)

\section{Element 10: Career and Technical Student Organizations:}

Description: The CTE program of study has a career and technical student organization (CTSO) as an intra-curricular and integral part of a curriculum and instruction that aligns with relevant program standards to develop employability and leadership skills through relevant developmental activities and competitive events.

\section{Key Indicators:}

1. Available to all students at some point during a CTE program of study

2. Alignment with relevant national, state, and/or local standards

3. Developing and reinforcing relevant academic, technical, and employability knowledge and skills

4. Providing opportunities for business and industry interactions, community and school service, competitive events, and leadership development

5. Supervised by CTE advisors with clear and defined roles

\section{Element 11: Work-Based Learning:}

Description: The CTE program of study provides work-based learning (WBL) experiences to develop and reinforce essential technical, academic, and employability skills. Students have opportunities to interact with business professionals, employers, and industry staff.

\section{Key Indicators:}

1. Organized in a sequenced continuum progresses in intensity in forms of workplace tours, job shadowing, schoolbased enterprises, laboratory work experience, internships, apprenticeships, cooperative learning, and community services

2. Accessible to all students

3. Guided by requirements and procedures addressing the access, selection, liability, supervision, safety, transportation, learning objectives, and evaluation of WBL experiences

4. Orientation provided to students and employers in advance of WBL

5. Alignment with program curriculum standards

6. Complying with relevant federal, state, and local laws and regulations

7. Learning experiences supervised by CTE educators and/or appropriate staff with defined roles

8. Learning experiences reflected and documented through a portfolio and/or presentation

9. Collaboratively planned, developed, and managed by students, teachers, and employers (e.g., $A L, M A, N V, N Y$ )replace 11-k in the ACTE framework

10. Available guidelines for student $W B L$ placement (e.g., MI)

\section{Element 12: Data and Program Improvement:}

Description: The CTE program of study evaluates all quality indicators to improve program through collected data that is to be shared with relevant stakeholders in a reliable, valid and easy-to-understand format.

Key Indicators:

1. Systematic and continuous use of student performance data

2. Timely and accurate collection and submission of data for required reporting through collaborative process

3. Privacy and security protections for data collection, storage, analysis, and reporting

4. Access to valid and reliable aggregate and disaggregated data

5. Shared with students, parents/guardians, partners and the community, as appropriate

6. All student performance meeting or exceeding the state-level targets (e.g., AZ, CA, IA, ME, MA, NH, NJ, SC, WI)

7. Documented student placement, employment records, follow-ups, and feedback for program improvement (e.g., $C A, C O, I D, N V, S D)$

Element 13: Legislation and Policies:

Description: Effective legislation and policies are available to promote the CTE program of study development and implementation.

Key Indicators:

1. Providing state and/or local funding and other resources for program improvement (e.g., professional development opportunities, facilities and equipment)

2. Establishing formal procedures for the design, implementation, and continuous improvement of a program of study 
3. Clear description of admissions, policies and procedures, selection criteria, enrollment conditions, and appeals processes

4. Ensuring opportunities for every student to participate in a program of study and to earn post-secondary credits and industry credentials

5. Ensuring the review and evaluation of student outcome data including achievement gaps

6. Requirement of individual graduation or career plan for students

7. $\quad$ Providing resources for long-term sustainability of the program of study

\section{Element 14: Program Administration:}

Description: District and school administrators understand and demonstrate support for the CTE program of study. Key Indicators:

1. Administration is responsible for the cohesive and seamless implementation of CTE programs

2. Coordination and evaluation of funding, program inventory, fiscal records, and instructional leadership in accordance with CTE policies and guidelines

3. Systems and structures developed and maintained to routinely communicate with CTE staff and advisory committee(s)

4. Written Five-Year Plan addressing facilities, equipment, curriculum, and staff development, which is developed with input from an advisory committee and is on file with the school administrator and updated annually

5. An annual program budget developed collaboratively by the teacher and school/district administration to provide adequate funding for program function

6. Student recruitment and sustainability plan developed, implemented, and updated annually

7. Economic market demands, both current and projected, are evaluated to determine the need for the CTE program and provide value-added opportunities for student learning 